\title{
Understanding the Impact of the Cultural Factors on Hospital Information System Acceptance: A Literature Review and Proposal of a New Model
}

\author{
Benali Idrissi Ouiame (PhD Student) \\ Chafik Khalid (Professor) \\ Boubker Omar (PhD)
}

Research Group "Management \& Information Systems", National School of Business and Management of Tangier, Abdelmalek Essaadi University, Tangier, Morocco

Doi:10.19044/esj.2018.v14n17p214 URL:http://dx.doi.org/10.19044/esj.2018.v14n17p214

\begin{abstract}
The behavioural intention to accept information system technologies remains an interesting research field for information system management specialists and researchers. However, the cultural dimension has rarely been treated by researchers in the healthcare context. This paper focuses on identifying the impact of national culture on users' intention to accept the Hospital Information System in public healthcare establishments in Morocco. Thus, we propose a research model which is based on a strong literature review, taking into consideration the previous studies' recommendations and limitations. The proposed model was developed through the extension of the Technology Acceptance Model (TAM) (Davis, 1989), by Hofstede's cultural dimensions.
\end{abstract}

Keywords: Health information technology, national culture, Public Hospitals, Technology Acceptance Model (TAM)

\section{Introduction}

Hospitals and medical organizations constitute a complex system which combines several units (care, administrative, med-technicians, pharmacy, logistics), and include uncountable operations and complicated processes. This complexity deteriorates even more by considering the technological and medical progress, and the enormous quantity of produced information (medical and administrative information).

Therefore, the Health Information System (HIS) in fact represents a strategic choice. These systems allow to store, to pass on, and to facilitate the management of informative flows which are essential for care production. 
The integration of the HIS improves health care quality, increases administrative efficacy, and reduces healthcare costs.

Several researches have studied the affecting factors on user behavioral intention toward accepting information system at health establishments (Egea \& González, 2011; Hsieh, 2015). However, the cultural dimension has rarely been treated by researchers.

In 2010,Oumlil led a study in 10 urban healthcare centers and the regional hospital Hassan II of the city of Agadir, located in the south of Morocco, in order to identify prediction factors affecting the intention of Communication and Information Technology (CIT) and Information Systems (IS) appropriation by healthcare professionals (physicians, nurses). The author developed a multidimensional model, which was inspired by Technology Acceptance Model (TAM) (Davis, 1989) and its most known extensions until 2003. The model integrates at the same time the individual, organizational, and technological dimensions. The research revealed that only the individual's beliefs, the organization structure, and the technology used affected the intention of ICT/IS appropriation. To appreciate the variation of the hypothetical model's results, the author considered the integration of the cultural factors (Hofstede, 1994), an interesting case of investigation.

However, our research study represents a continuity of this work and its main purpose is to investigate the impact of the national culture on the user acceptance of the hospital information system in Morocco.

\section{Theoretical Background}

Nowadays, information systems theoretical approaches have been extensively coexisting in information systems management (Boubker \& Chafik, 2016, 2017). In order to choose a suitable approach, it remains important to position it according to the investigated object.

In fact, the behavioural approach is applied in a determinist perspective, dedicated to predict and understand the existing link between attitudes and behaviour of an individual through the concept of « behavioural intention », and also to understand the link between this behaviour and the failure or success of information system acceptance in organisations (Kukafka et al., 2003; Baile, 2005). This approach supposes that the intentions crystallize the motivational factors which influence a behaviour through the indication of people's willing degree and the effort they are ready to realize (Ajzen, 1991).

The main objective of this approach is to understand the influence of the motivational factors on the behavioural intention (Quiguer, 2013).

In this paper, we are going to present the most relevant behavioural intention models and theories, in order to develop our theoretical model. 


\section{Prediction of Behavioural Intention Theories}

One of the most important behavioural intention basic models is the theory of reasoned action (TRA). Throughout the time, it has known several extensions and adaptations, which ended into new models and theories, such as the theory of planned behaviour (TPB) and the theory of interpersonal behaviour (TIB).

The theory of reasoned action (Fishbein, 1975; Azjen, 1980) is based on the supposition that individuals' intention to adopt technology is determined by personal interest (attitude) and social influence (subjective norms). The " attitude » is influenced by individuals' predisposition to favourably or unfavourably evaluate technology adoption. "The subjective norms» corresponds to the social influence of individuals intention to realize such behaviour, the perception of others expectations, multiplied by the motivation degree to conform to their expectations (Figure 1).

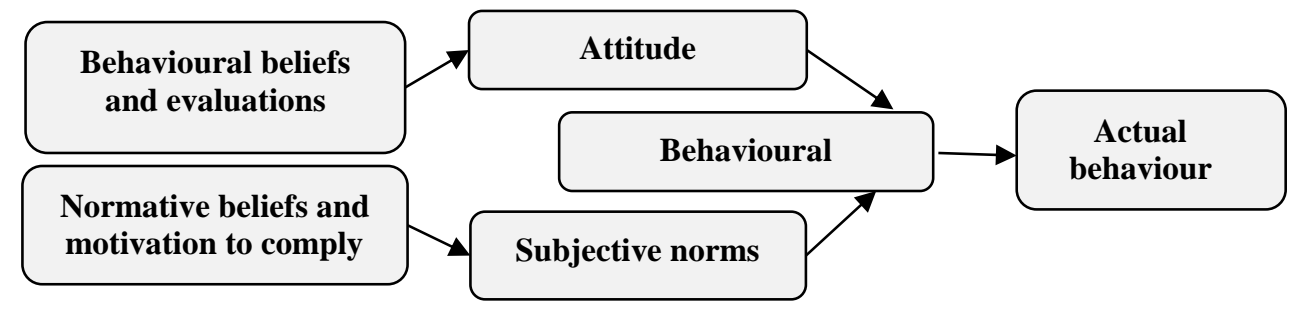

Figure 1. Theory of reasoned action (Fishbein, 1975; Azjen, 1980)

In 1991, Ajzen proposed the Theory of planned behaviour (TPB), as an extention of TRA which introduces new construct, «the perception of behaviour's control». Kukafka et al. (2003) indicated through this theoretical extension that «the behaviour» is determined by motivation (behavioural intention) and capacity (behavioural control). Nevertheless, «behavioural intention» is influenced by «attitude», «the subjective norms», and " the control of perceived behaviour ", which act at the same time on individuals' intention and behaviour (Figure 2).

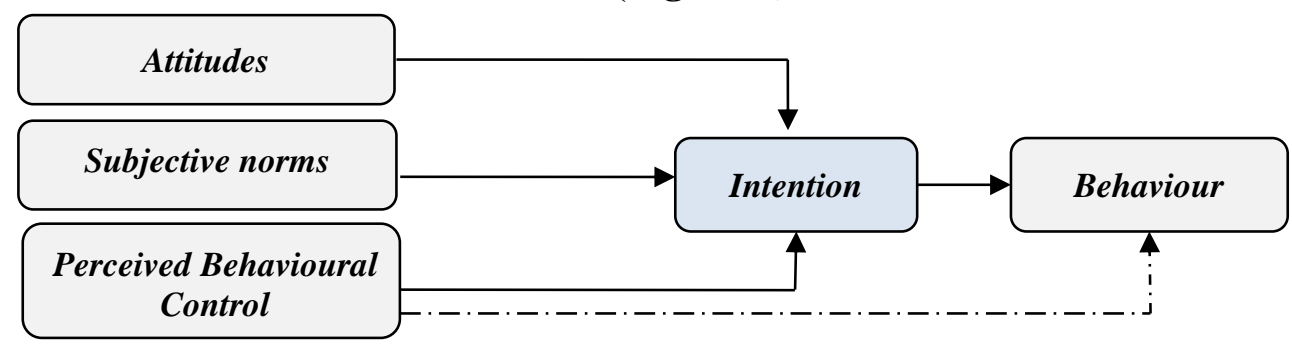

Figure 2. Theory of planned behavior (Ajzen, 1991, p. 182)

Triandis (1980) holds the theory of reasoned action principles and variables to develop the theory of interpersonal behaviour (TIB). The author 
distinguishes between emotional beliefs related to actions and those related to future consequences, unlike the theory of reasoned action which incorporates all kind of beliefs into the same group (Figure 3).

According to TIB, the " behaviour » results from three determiners: the intention to adopt behaviour, the habit, and facilitating conditions.

The intention is considered as the key variable of the framework model due to expressing individual's motivation to adopt certain behaviour. Indeed, intention is determined by three variables: «The attitude » or affect, which is the positive or negative feeling of individuals to adopt a behaviour; " the social norms " which represent the perception towards reference groups' culture to which they belong or whom they interact with most frequently; the " Perceived Consequences » expected from their behaviours. Conforming to Triandis (1980), «attitudes» are influenced by « habits » and «cultural perceptions » of individuals.

External variables (History, culture, ecology, social situation, genetic, personality, etc)

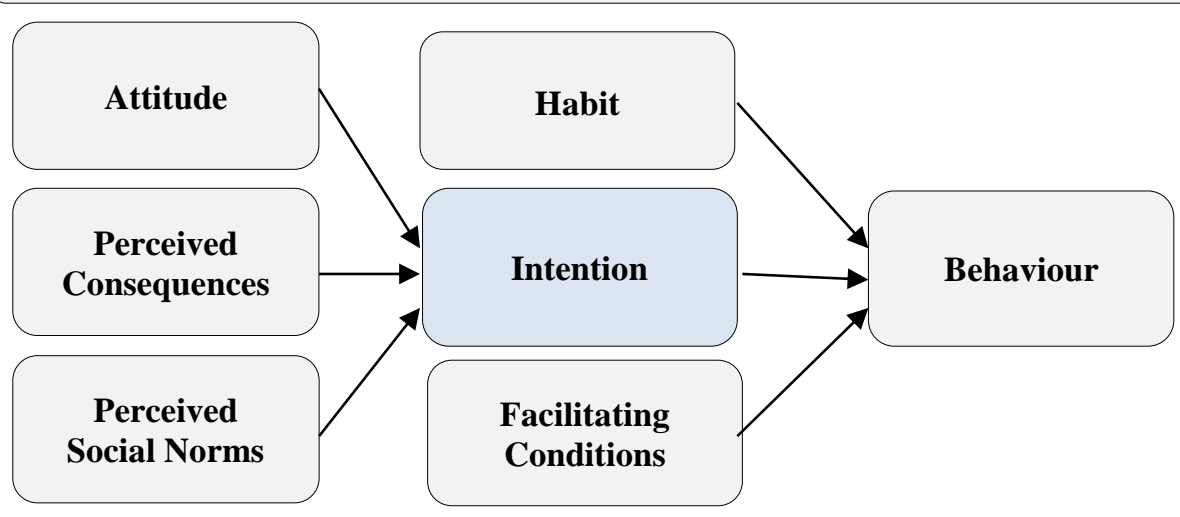

Figure 3. Theory of interpersonal behaviour model (Traindis, 1980)

\section{Culture and Information System Acceptance}

The literature shows that culture's concept was extensively studied by information system management researchers. It was studied frequently at Technology acceptance context with the purpose of capturing cultural influence on individuals' intention (Evers \& Day, 1997; Srite \& Karahanna, 2006; Cardon \& Marshall, 2008; Vörös \& Choudrie, 2011).

Ein-Dor et al. (1993), Palvia (1998), and Harvey (1999) considered the cultural variables as the key on information system's adoption.

Based on the theory of planned behaviour, intention is leading frequently to the actual behaviour (Ajzen, 1991). Moreover, Cameron (2008) indicated that culture influences behaviour, thoughts, and individual's emotions. Thus, we can say that there is a certain relationship between the 
following three variables: culture, intention, and behaviour.

In 2001, Straub, Loch, and Hell examined the impacts of beliefs and values on IT transfer in Arab countries. They concluded that the cultural beliefs are the most powerful prediction factors of IT resistance.

In fact, the first confronted challenge during cultural research appears on the understanding of its definition, conceptualization, and its dimensions used to describe its concept (Straub et al., 2002). For this reason, several researchers tried to define culture notion. For example, Kroeber and Kluckhohn (1952, p.181) identified 164 definitions of culture, stating: «Culture consists of patterns, explicit and implicit, of and for behaviour acquired and transmitted by symbols, constituting the distinctive achievements of human groups, including their embodiment in artefacts; the essential core of culture consists of traditional (i.e. historically derived and selected) ideas and especially their attached values; culture systems may, on the one hand, be considered as products of action, on the other, as conditional elements of future action».

This definition represents the beginning of the psychologist Geert Hofstede (1991) reflection towards his culture approach.

\section{Hofstede's Cultural Dimensions}

Hofstede (2011, p. 2) defined culture as "the collective programming of the mind that distinguishes the members of one group or category of people from others".

He led a survey between 1967 and 1972 and developed his model based on over 116,000 survey responses in the IBM in seventy-two units in 60 countries. His aim was to define differences among cultural factors, and to show their impacts on management, firms, and organization (Loth, 2006). The obtained results allowed him to release four major dimensions in classifying countries:

$\checkmark \quad$ Power Distance;

$\checkmark \quad$ Individualism vs. Collectivism;

$\checkmark \quad$ Masculinity vs. Feminism;

$\checkmark \quad$ Uncertainty Avoidance.

However, these dimensions can be defined as follows. 


\begin{tabular}{|c|c|c|}
\hline $\begin{array}{c}\text { Dimension } \\
\text { Index }\end{array}$ & $\begin{array}{c}\text { Definition } \\
\text { Power Distance } \\
\text { within a country expect and accept that power is distributed unequally. }\end{array}$ \\
\hline $\begin{array}{c}\text { The degree to which people in a society are integrated into groups. On the } \\
\text { individualist side, we found cultures in which the ties between individuals are } \\
\text { loose: everyone is expected to look after him/herself and his/her immediate } \\
\text { family. On the collectivist side, we found cultures in which people from birth } \\
\text { onwards are integrated into strong, cohesive in-groups, often extended families } \\
\text { (with uncles, aunts and grandparents) that continue protecting them in exchange } \\
\text { for unquestioning loyalty, and oppose other in-groups. }\end{array}$ \\
$\begin{array}{c}\text { Masculinity/ } \\
\text { Femininity } \\
\text { another fundamental issue for any society, to which a range of solutions can be } \\
\text { found. Men's values from one country to another contain a dimension from } \\
\text { very assertive and competitive and maximally different from women's values } \\
\text { on the one side, to modest and caring and similar to women's values on the } \\
\text { other. The assertive pole has been called "masculine" and the modest, caring } \\
\text { pole "feminine". }\end{array}$ \\
\hline $\begin{array}{c}\text { Uncertainty } \\
\text { Avoidance Index }\end{array}$ & $\begin{array}{c}\text { It indicates to what extent a culture programs its members to feel either } \\
\text { uncomfortable or comfortable in unstructured situations. Unstructured } \\
\text { situations are novel, unknown, surprising, and different from usual. }\end{array}$ \\
\hline
\end{tabular}

Table 1. Hofstede's Cultural Dimensions and Effects definitions (Hofstede, 2011, pp. 9-12)

The estimated analyses of Hofstede's cultural dimensions score for Morocco (Figure 4), shows that «Power distance » (70) and « uncertainty avoidance » (68) are the dominant characteristics. «Power distance» score of 70 indicates the high level of power disparity and wealth. The «uncertainty avoidance» score (68) classifies Morocco among the cultures which prefer the tested and used ways instead of taking the risk and trying new methods and technologies to minimize their uncertainty.

The high score of Masculinity dimension (53) means that Moroccans are more declarative and competitive and they are less modest and thoughtful.

Finally, with the individualism score (46), Morocco is considered as a collectivist society based on long-term commitment towards a group of members: family, a widened family or prolonged relations.

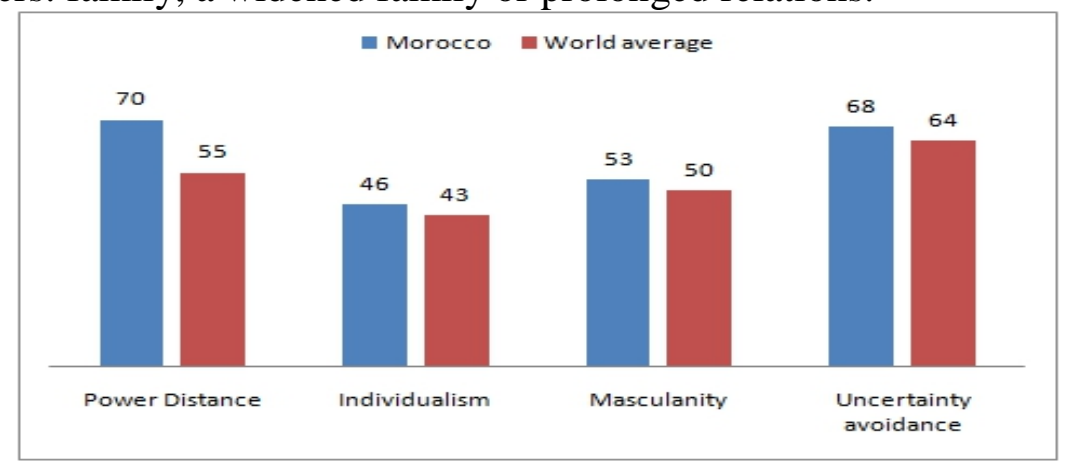

* Hofstede's estimated values

Figure 4. Hofstede's cultural dimensions for Morocco 
The Hofstede's model was mobilized in different research fields and contexts. Its cultural dimensions were also used in many information system studies (Myers \& Tan, 2003; Lee et al., 2013). Findings show that national culture has a significant relation with the technological transfer, information's national infrastructure, and technology usage rate.

Straub, Keil and Brenner (1997) have tested the TAM in three countries: Japan, Switzerland, and United States. The Japanese TAM adoption was insignificant while it is well explained for IT use in Switzerland. This difference is due to the national culture's influence.

In their study of Information and Communication Technology (ICT) adoption, Hasan and Ditsa (1999) made a survey in western Africa, the Middle East, and in Australia. The results confirmed that culture directly influences the ICT usage in several countries.

In 2008, Cao and Everard led a study to show the relationship between national cultures' values and individuals' attitudes towards the use of instant messaging through the mediation of their perceptions in terms of privacy and awareness. The results confirmed that the users' attitude is positively influenced by their perceptions of private personal life and raising awareness. They are even impacted by the avoidance of uncertainty, evident in «uncertainty avoidance».

El Garah, Veltri and Krasnova (2011) led a comparative study to understand national culture's role in social networks usage, especially Facebook by Moroccan and American users. The survey findings showed that Moroccan users are more discreet on social media than the American users, and they experience more damages if their privacy is violated.

Nevertheless, American users have lower concerns in regards to their private life's protection and much trust via their followers on Facebook. As a result, they reveal more information on their profiles. From a practical standpoint, the social networks suppliers cannot lean on the same methods to encourage the participation and the disclosure of users in various countries.

\section{Research framework}

The literature review shows that there is a variety of models. However, the Technology Acceptance Model (TAM) is considered as the most used theoretical reference to predict new IT acceptance (Schepers \& Wetzelts, 2007).

\section{Technology Acceptance Model (TAM)}

In 1989, Davis adapted the theory of reasoned action (Fischbein 1975, Ajzen1980) in order to introduce the TAM (Technology Acceptance Model). In fact, Davis developed this model to explain individuals' behaviour towards computers. 
TAM leans on the hypothesis that technology use is determined by the behavioural intention under the influence of individuals' attitude of using technology, and the perceived usefulness (PU), which was defined by Davis as "the degree to which a person believes that using a particular system would enhance his or her job performance." The attitude is impacted by the Perceived Usefulness (PU) and the Perceived Ease of Use (PEOU) which is "the degree to which a person believes that using a particular system would be free from effort" (Davis, 1989).

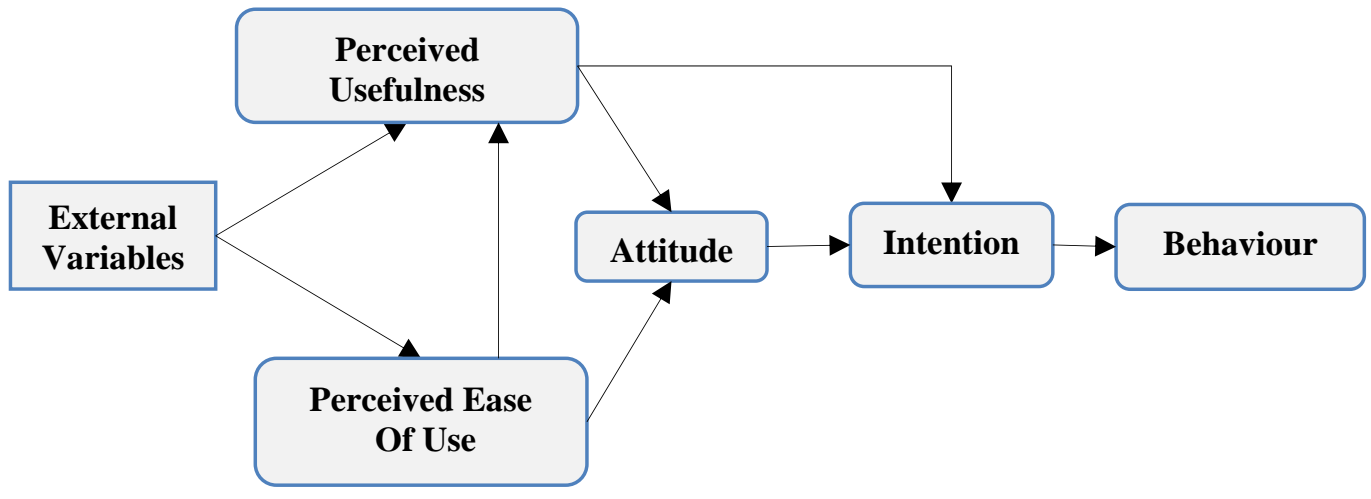

Figure 5. Technology Acceptance Model (Davis, 1989, p.985)

This model has been extended several times. The most remarkable ones are the TAM2, proposed by Venkatesh and Davis (2000) and TAM3 proposed by Venkatesh and Bala (2008).

TAM model was adopted as a reference in different context because of the precision and specificity of its dimensions (Mathieson, 1991; Adams, 1992; Chau, 2001, 2002; Szajna, 1996; Venkatesh, 2000; Chafik \& Boubker, 2016; Muñoz-Leiva, Climent-Climent \& Liébana-Cabanillas, 2017; Wu \& Chen, 2017). However, it remains limited in healthcare context (Agglidis \& Chatzoglou, 2009).

\section{TAM Use in Healthcare Context}

One of the first uses of TAM in a healthcare context was in 1999 by Hu, Chau, Sheng, and Tam. These authors examined the feasibility of TAM to predict the decision of telemedicine's acceptance by physicians. They adopted this research model with the abstraction of "real behavior" variable. The results concerned 408 tertiary public hospital physicians of Hong-Kong, and they confirmed that perceived usefulness has a positive and significant influence on the physicians' intention to use technology more than the attitude. Yet, explaining intention and attitude via TAM remains a very underdeveloped practice.

Holden and Kash (2010) realized a meta-analysis about TAM use in 
the healthcare system by analyzing 20 studies made between 1999 and 2008 . The results of this study showed that the TAM predicts, considerably, the acceptance of technologies in healthcare context. This is with the addition and the modification of certain variables in the model, because the causal links of the model are not all significant. Thus, they recommended the adaptation of this model to healthcare context in the future studies by using incentive beliefs methods.

On the other hand, Wu, Li and Fu (2011) proposed a model based on TAM and the theory of planned behaviour to understand mobile technology adoption by healthcare professionals in Taiwan. The empirical study, made up of 80 hospitals with a response rate of $17.5 \%$, showed that the perceived intention is very high. Besides attitude, the perceived usefulness, the perceived control, and the subjective norms are the most significant variables which influence medical mobile technology's acceptance by the healthcare professionals (physicians and nurses).

To predict the behavioural intentions to accept or reject using "elearning" by students, Chow et al. (2012) mobilized for this purpose the TAM, widened by «the auto-efficiency », as an external variable. 206 nursing students participated in this study. In fact, the results confirmed the perceived usefulness of the system by students. Nevertheless, they remained neutral concerning its ease of use. In this context, TAM is considered the strongest model because every model's variables have a significant influence according to the study statistics.

In 2015, Hsieh developed an integrated model by combining the theory of planned behaviour's model with the theory of «Status quo bias » to explain the intention of acceptance and resistance towards using «cloud computing» technology by healthcare professionals in Taiwan. The results of the study, with a sample of 209 healthcare professionals, yielded a response rate of $69.67 \%$ among which $34.45 \%$ of physicians, $53.11 \%$ of nurses, and $12.44 \%$ of other professionals revealed that the attitude, the subjective norms, and the perceived control have a positive and direct influence on professionals' intention to use «cloud-computing» technology. They also indicated that there is a negative and significant effect in relation between intention and the resistance of technology use.

In the Moroccan context, the studies of users' behavioural intention prediction concerning IS use and technology acceptance remains very limited in healthcare sector, according to our literature review.

In 2014, Bennani, Oumlil and Grenier led a study among 10 urban health centres and the regional hospital Hassan II of the city of Agadir, in the south of Morocco, to identify the most significant factors of ICT/IS prediction by healthcare professionals (physicians, nurses). They developed a multidimensional model inspired by TAM based on the study of Davis 
(1989) and its common extensions until 2003. The model integrates at the same time the individual, organizational, and technological dimensions.

The survey results showed 111 responses, of which 37 were physicians and 108 nurses, with a response rate of $76.55 \%$. It has been confirmed that the intention to accept ICT/IS by healthcare professional users is influenced by individuals beliefs, the organization's structure, and technology use. The regression analysis allowed us to identify the most significant factors to predict IT use, namely: Attitude, Image, compatibility, Perceived usefulness, and ease of use.

\section{The TAM Model and Hofstede's Cultural Dimensions}

The influence of cultural differences on technology use and information systems oriented certain authors to propose extensions of TAM model by adding Hofstede's cultural dimensions (Al-Jaafreh \& AlAbedallat, 2012).

The culture's impact on TAM variables was explored as well by several researchers in different contexts (Straub, 1994; Tan et al., 1995; Hasan \& Ditsa, 1999; Straub et al., 2001; VanSlyke et al., 2005; Cao \& Everard, 2008).

Srite and Karahanna (2006) extended TAM model by using cultural dimensions as moderator variables to study Hofstede's national cultural values role on information technology IT acceptance. They examined the impact of these variables on the relationships between perceived usefulness and behavioural intention to use, the relationship between ease of use and behavioural intention, and the relation between subjective norms and behavioural intention.

To test their theoretical model, these researchers conducted two studies. The results showed that the social norms are the strongest determiners of behavioural intention for individuals with «feminine» cultural values and higher level of «uncertainty avoidance», and «Masculinity» as influencing moderating variable based on the relationship between perceived ease of use and behavioural intention. In spite of both studies' results differences, " the uncertainty avoidance» appears as the moderating variable with significant and constant influences on the relation between the subjective norms and the behavioural intention.

These two authors also compared their model with extended TAM proposed by Venkatesh et al. (2003) which includes the demographic moderating variables (Age, sex and experience and their interactions). The explained variance of these models varied from $33,8 \%$ to $48,7 \%$. Consequently, they concluded that the addition of Hofstede's cultural values constructs increased the explanatory power of extended TAM. Also, it is similar or equal to models which include the demographic moderating 
variables of technology acceptance.

In 2011, Al-Hujran et al developed TAM's integrated model extended by cultural dimensions of Hofstede to estimate the impact of the latter on the adoption of « e-government » services in Jordan. The collected data amongst 197 Jordanian citizens showed that only «Power distance» and «uncertainty avoidance» have a significant influence on citizens' intention towards using e-services. The perceived usefulness» and «the perceived ease-of-use» are also significant variables which impact considerably Jordanians' behavioural intention to use.

Hoque and Bao (2015) examined the influence of cultural factors on « e-health » professional use by patients, physicians, and nurses in both public and private hospitals of Bangladesh, through Hofstede's cultural values modifications on TAM. The results confirmed that «Power distance», «Masculinity», and «Perceived ease-of-use» have a significant impact on the intention to use electronic health applications.

\section{Research Model And Hypothesis}

Based on the analysis and recommendations of the previous studies, we developed our research model which combines the TAM's variables and the national culture dimensions of Hofstede (2011). In addition, we also combined other variables that we deem necessary to study the impact of the national culture on HIS Acceptance in healthcare Moroccan context.

\section{Variables and Research Hypothesis}

The theoretical reflections were essential to understand the interaction between the variables of our research model and to identify variables that might affect directly or indirectly the intention to accept the HIS.

\section{Perceived Usefulness}

It is one of the principal components of TAM model. Davis supposes that the "Perceived Usefulness" impacts positively the intention to use a Technology. This relationship was confirmed in several research works in different contexts (Davis, 1989; Igbaria et al., 1997; Venkatesh \& Davis, 2000; Chau \& Hu, 2002; Venkatesh \& Balla, 2008; Al-Hujran \& al., 2011).

Also, this can be seen in the context of healthcare (Chau, Sheng $\&$ Tam, 1999; Croteau \& Vieru, 2002; Bennani et al., 2008; Wu, Li \& Fu, 2011; Chow et al., 2012; Hoque \& Bao, 2015). The first hypothesis stipulates that:

H1: "Perceived Usefulness" has a direct positive effect on the intention to accept the HIS. 


\section{Perceived Ease of Use}

The second hypothesis concerns the relation between the "Perceived Ease of Use" and the Behavioral intention. It supposes that the intention to use a technology is affected by the belief degree on its simple use. This relation was validated in several studies in different contexts (Davis, 1989; Venkatesh, 2000; Venkatesh \& Balla, 2008; Al-Hujran et al., 2011; Hoque \& Bao, 2015) and in the context of health care also (Croteau \& Vieru, 2002; Wu et al., 2008; Aggelidis \& chatzoglou, 2009). The hypothesis stipulates that:

H2: "Perceived Ease of Use" has a direct positive effect on the intention to accept the HIS.

The third hypothesis supposes a significant positive relationship between the "Perceived Usefulness" and the "Perceived Ease of Use". Many authors confirmed this relation in different contexts (Davis, 1989; Venkatesh, 2000; Venkatesh \& Balla, 2008; Al-Hujran et al., 2011; Hoque \& Bao, 2015) and also in the healthcare context (Croteau \& Vieru, 2002; Wu et al., 2007; Wu et al., 2011). The hypothesis stipulates that:

H3: "Perceived Ease of Use" has a direct positive effect on the Perceived usefulness.

\section{Attitude}

The fourth hypothesis concerns the effect of the attitude on the intention to accept HIS. Based on the (TAR) model, the attitude influences the behavioral intention. This relation was confirmed empirically in different contexts (Hartwick et al., 1994; Chau \& Hu, 2002), including health care context (Ryu et al., 2003; Mohd \& Syed Mohamad, 2005; Hung, Ku \& Chien, 2012).

Egea and Gonzalez (2011) and Hsieh (2015) pointed out that the attitude is the most decisive predictive factor in the doctor's intention to use the IT. Thus, we propose the following hypothesis about the attitude and the behavioral intention. The hypothesis stipulates that:

H4: Attitude toward using IT has a direct positive effect on intention to accept the HIS.

\section{Subjective Norms}

The fifth hypothesis concerns the relation between the subjective norms and the behavioral intention. The subjective norms express that a person's behavior is related to his normative beliefs regarding other people's expectations. The more they perceive that others think that they should engage in a behavior, the greater their motivation to comply (Hsieh, 2015).

In the healthcare context, past studies have provided the empirical evidence to confirm that the variable, subjective norms, is one of the main 
determinants of the behavioral intention towards using IT (Chau \& $\mathbf{H u}$, 2002; Hung et al., 2012; Hsieh, 2015). Thus, we propose the following hypothesis:

H5: "Subjective norms" have a direct positive effect on the "intention" to accept the HIS.

\section{Collectivism}

The sixth and seventh hypothesis concerns the relationship between "collectivism", the "perceived usefulness", and the "perceived ease of use". Akour et al. (2006) confirmed that this cultural dimension has a direct positive effect on the perceived usefulness and the perceived ease of use. Thus, we propose the following hypothesis:

H6:Collectivism has a direct positive effect on the Perceived usefulness.

H7:Collectivism has a direct positive effect on Perceived ease of use.

\section{Power Distance and Uncertainty Avoidance}

Akour et al. (2006) stated that the perceived usefulness and the perceived ease of use positively mediate the impact of power distance on the usage intention. In addition, the "perceived ease of use" increases the impact of "uncertainty avoidance" on the manager's intention to use internet. AlHujran et al. (2011) confirm in their study that among the cultural dimensions of Hofstede (2011), only the "Power distance" and the "Uncertainty avoidance" influence positively and significantly the "Perceived usefulness" and the "Perceived ease of use". Thus, we propose the following hypothesis:

H8: Power distance has a direct positive effect on the perceived ease of use.

H9: Uncertainty avoidance has a direct positive effect on perceived usefulness.

H10: Uncertainty avoidance has a direct positive effect on perceived ease of use.

In cultures with high levels of "Uncertainty avoidance", individuals often consult their social circle (family, friends...) to ensure that the acceptance of a technology is appropriated (Rice \& Aydin, 1991). Hence, those people could be used to encourage others to adopt or use such technology.

Strite and Karahanna confirmed this relation in 2006. They stated that the "Uncertainty avoidance" works as a moderating variable, and has a significant impact on the relation between the "Subjective norms" and the "Behavioral intention". In addition, this effect is stronger in individuals with a very high level of "Uncertainty avoidance". 
H11: The relationship between subjective norms and "Intention" to accept HIS is moderated by "uncertainty avoidance".

\section{Masculinity}

The influence of the masculinity variable in the TAM depends on the cultural context.

Srite and Karahanna (2006) confirmed that the relation between subjective norms and intention is moderated by the masculinity cultural value in female cultures, while it moderates the relation between perceived ease of use and behavioral intention in masculine cultures.

Morocco has a masculine culture as stated above. Thus, we propose the following hypothesis:

H12: The relationship between perceived ease of use and intention to accept HIS is moderated by Masculinity.

The following table synthesizes the variables and hypothesis of our theoretical model.

\begin{tabular}{|c|c|c|}
\hline Variables & Hypothesis & Authors \\
\hline $\begin{array}{l}\text { Perceived } \\
\text { Usefulness }\end{array}$ & $\begin{array}{l}\text { H1: Perceived usefulness has a } \\
\text { direct positive effect on the } \\
\text { intention to accept the HIS. }\end{array}$ & $\begin{array}{c}\text { Davis, 1989; Igbaria et al., 1997; } \\
\text { Venkatesh \& Davis, 2000; Chu \& Hu, } \\
\text { 2002; Venkatesh \& balla, 2008; Al-Hujran } \\
\text { et al., 2013; Chau, Sheng \& Tam, 1999; } \\
\text { Croteau \& Vieru, 2002; Bennani et al., } \\
\text { 2008; Wu, Li \& Fu, 2008, 2011; Chow et } \\
\text { al., 2012; Mooghali \& Mirghaderi, 2012; } \\
\text { Hoque \& Bao, } 2015\end{array}$ \\
\hline $\begin{array}{l}\text { Perceived Ease of } \\
\text { Use }\end{array}$ & $\begin{array}{l}\text { H2: Perceived Ease of Use has a } \\
\text { direct positive effect on the } \\
\text { intention to accept the HIS. } \\
\text { H3: Perceived Ease of Use has a } \\
\text { direct positive effect on the } \\
\text { Perceived usefulness. }\end{array}$ & $\begin{array}{l}\text { Davis, 1989; Venkatesh, 2000; Venkatesh } \\
\text { \& Balla, 2008; Mooghali \& Mirghaderi, } \\
\text { 2012; Al-Hujran et al., 2013; Hoque \& } \\
\text { Bao, 2015 } \\
\text { Davis, 1989; Croteau \& Vieru, 2002; Wu } \\
\text { et al., 2008, 2011; Agglidis \& Chatzoglou, } \\
\text { 2009; Mooghali \& Mirghaderi, 2012 }\end{array}$ \\
\hline Attitude & $\begin{array}{l}\text { H4: Attitude toward using IT has a } \\
\text { direct positive effect on intention } \\
\text { to accept the HIS. }\end{array}$ & $\begin{array}{c}\text { Hartwick et al., 1994; Chau \& Hu, 2002; } \\
\text { Ryu et al., 2003; Mohd \& Syed Mohamad, } \\
\text { 2005; Hung, Ku \& Chien, 2012; Egea \& } \\
\text { González, 2011; Hsieh, 2015 }\end{array}$ \\
\hline Subjective Norms & $\begin{array}{l}\text { H5: Subjective norms have a direct } \\
\text { positive effect on the intention to } \\
\text { accept the HIS. }\end{array}$ & $\begin{array}{c}\text { Chau \& Hu, 2002; Srite \& Karahanna, } \\
\text { 2006; Hung et al., 2012; Wu, Li \& Fu, } \\
\text { 2008, 2011; Hsieh, } 2015\end{array}$ \\
\hline Collectivism & $\begin{array}{c}\text { H6: Collectivism has a direct } \\
\text { positive effect on the Perceived } \\
\text { usefulness. } \\
\text { H7: Collectivism has a direct } \\
\text { positive effect on Perceived Ease } \\
\text { of Use. }\end{array}$ & Akour et al. (2006) \\
\hline Power Distance & $\begin{array}{l}\text { H8: Power distance has a direct } \\
\text { positive effect on the perceived } \\
\text { ease of use. }\end{array}$ & $\begin{array}{l}\text { Akour et al. (2006) } \\
\text { Al Hujran et al. (2011) }\end{array}$ \\
\hline $\begin{array}{l}\text { Uncertainty } \\
\text { Avoidance }\end{array}$ & $\begin{array}{l}\text { H9: Uncertainty avoidance has a } \\
\text { direct positive effect on perceived }\end{array}$ & $\begin{array}{c}\text { Akour et al. (2006) } \\
\text { Al Hujran et al. (2011) }\end{array}$ \\
\hline
\end{tabular}




\begin{tabular}{|l|c|c|}
\hline & $\begin{array}{c}\text { usefulness. } \\
\text { H10: Uncertainty avoidance has a } \\
\text { direct positive effect on perceived } \\
\text { ease of use. }\end{array}$ \\
$\begin{array}{c}\text { H11: The relationship between } \\
\text { subjective norms and "intention" to } \\
\text { accept HIS is moderated by } \\
\text { uncertainty avoidance. }\end{array}$ & Strite \& Karahanna (2006) \\
\hline Masculinity & $\begin{array}{c}\text { H12: The relationship between } \\
\text { perceived ease of use and intention } \\
\text { to accept HIS is moderated by } \\
\text { Masculinity. }\end{array}$ & Srite \& Karahanna (2006) \\
\hline
\end{tabular}

Table 2. Summary table of research hypothesis

\section{Research Model}

Based on the above variables and hypothesis, we can propose our research Model.

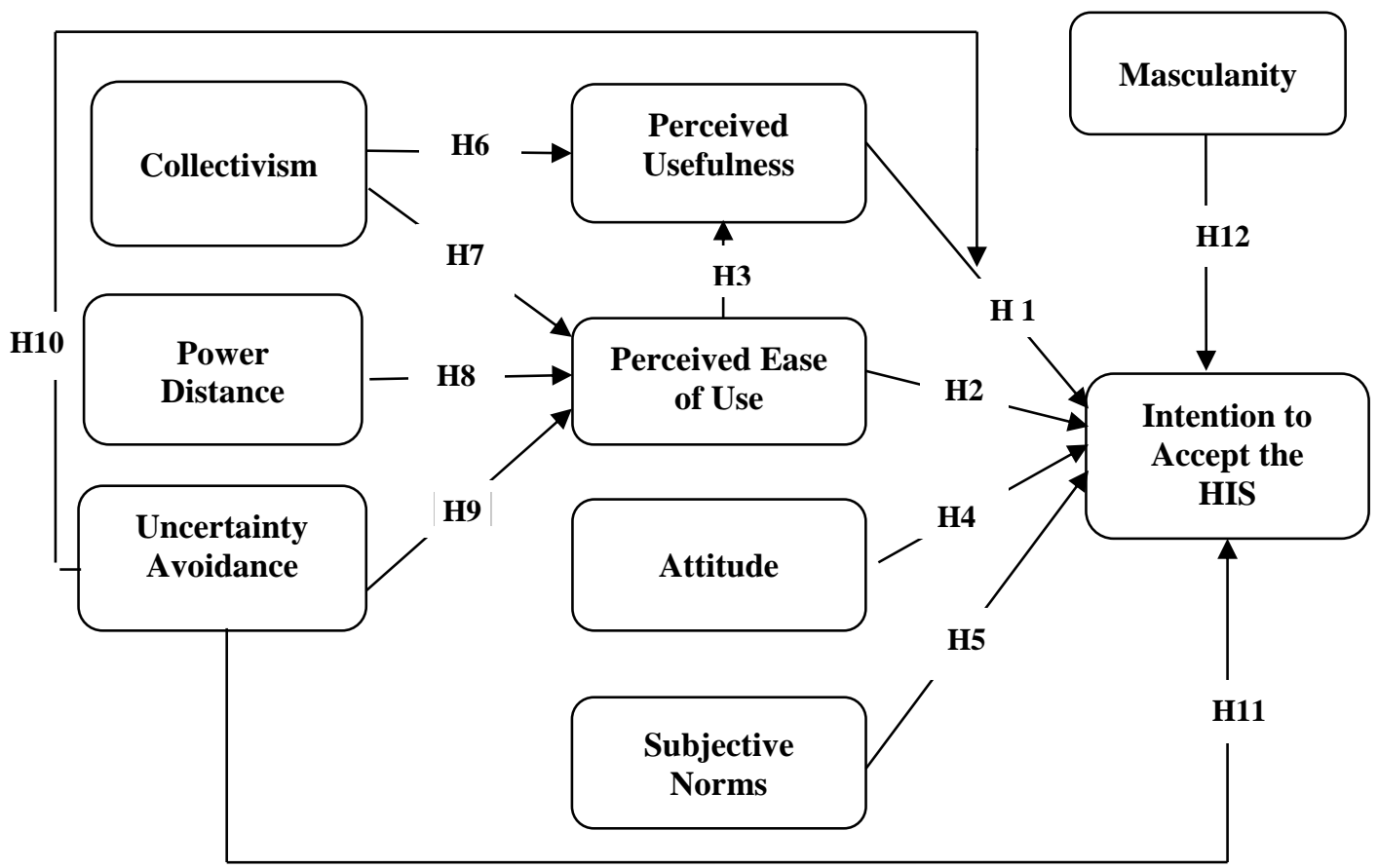

Figure 6. Research Model

\section{Conclusion}

We developed our research model, based on the literature review, to understand the impact of cultural factors on individual's intention to accept information technology system in healthcare context.

The model is based on an exploratory qualitative approach. Thus, we intend to mobilize a survey within healthcare professionals (Physicians, 
administrative, nursing) to contextualize our research model in the public Moroccan healthcare system.

The objective of this phase is to stabilize our conceptual model in order to fit in with the Moroccan reality. Once elaborated, it will be tested and confirmed through a quantitative approach.

\section{References:}

1. Adams, DA., Nelson, RR., \& Todd, PA. (1992). "Perceived usefulness, ease of use, and usage of information technology: A replication". MIS Quarterly, 16, 227-247.

2. Aggelidis, V. P. \& Chatzoglou, P. D. (2009).Using a modified technology acceptance model in hospitals. International journal of medical informatics, 78(2), 115-126.

3. Ajzen, I. (1991). "The theory of planned behavior". Organizational Behavior and Human Decision Processes 50: 179-211.

4. Ajzen, I. \& Fishbein, M. (1980). Understanding attitudes and predicting social behaviour.

5. Akour, I., Alshare, K., Miller, D., \& Dwairi, M. (2006). An exploratory analysis of culture, perceived ease of use, perceived usefulness, and internet acceptance: The case of Jordan. Journal of Internet commerce, 5(3), 83-108.

6. Al-Hujran, O. \& Al-dalahmeh, M. (2011). The Role of National Culture on Citizen Adoption of eGovernment web sites. In ECEG2011-Proceedings of the 11th European Conference on EGovernment: ECEG2011 (p. 17). Academic Conferences Limited.

7. Al-Jaafreh, A. B. \& Al-Abedallat, A. Z. (2012).The effect of national culture on the information quality in Jordan; Conceptual framework. International Journal of Economics and Research, 3(5), 22-40.

8. Baile, S. (2005). L'approche comportementale de l'évaluation des systèmes d'information : théories et taxonomie des modèles de recherche.Actes de l'université d'été de l'IAS, Lille.

9. Bennani, A., Belalia, M., \& Oumlil, R. (2008). "As Human Factor, the attitude of Healthcare Practitioners is the Primary Step for the eHealth: First Outcome of an Ongoing Study in Morocco, CIBIMA online journal, Volume 3, number 4.

10. Bennani, A., Oumlil R. \& Grenier, E. (2014). "Human Factors Influencing the Intention of ICTAcceptation by Healthcare Practitioners: A Survey In Public Centers In Agadir City, South Of Morocco", Journal of North African Research in Business, Vol. 2014, doi: 10.5171/2014.607571

11. Boubker, O. \& Chafik, K. (2016). Comprendre Le Role Des Systemes D'information Dans L'amelioration De La Performance Et 
La Maturite Des Processus Logistiques: Etude Qualitative Aupres De Six Entreprises De L'industrie Automobile Et Aeronautique Au Maroc. European Scientific Journal, 12(28), 397-429. doi: 10.19044/esj.2016.v12n28p397

12. Boubker, O. \& Chafik, K. (2017). An investigation of the relationship between logistics information quality and LIS use based on structural equation modelling approach: A case study of automotive and aerospace companies in Morocco. New Trends and Issues Proceedings on Humanities and Social Sciences, 4 (10), 97-109. doi:10.18844/prosoc.v4i10.3068

13. Cameron, K. (2008). A process for changing organization culture.Handbook of organizational development, 429-445.

14. Cao, J. \& Everard, A. (2008). User attitude towards instant messaging: the effect of espoused national cultural values on awareness and privacy. Journal of Global Information Technology Management, 11(2), 30-57.

15. Cardon, P. W. \& Marshall, B. A. (2008). National culture and technology acceptance: The impact of uncertainty avoidance. Issues in Information Systems, 9(2), 103-110.

16. Chafik, K. \& Boubker, O. (2016). Systèmes d'information, performance et maturité des processus: Élaboration d'un modèle théorique basé sur l'approche sociotechnique. International Journal of Innovation and Applied Studies, 16(1), 111-126.

17. Chau, P. Y. \& Hu, P. J. H. (2002). Investigating healthcare professionals' decisions to accept telemedicine technology: an empirical test of competing theories. Information \& management, 39(4), 297-311.

18. Chau, PYK., PJH. Hu. (2001). "Information Technology Acceptance by Individual Professionals: A Model Comparison Approach." Decision Sciences. 32(4): 699-719.

19. Chow, M., Herold, D. K., Choo, T. M., \& Chan, K. (2012).Extending the technology acceptance model to explore the intention to use Second Life for enhancing healthcare education. Computers \& Education, 59(4), 1136-1144.

20. Croteau, A. M., \& Vieru, D. (2002). Telemedicine adoption by different groups of physicians. In System Sciences, 2002.HICSS. Proceedings of the 35th Annual Hawaii International Conference on (pp. 1985-1993). IEEE.

21. Davis, F. D., Bagozzi, R. P., \& Warshaw, P. R. (1989). User acceptance of computer technology: a comparison of two theoretical models. Management Science, 35(8), 982-1003. 
22. Egea, J. M. O. \& González, M. V. R. (2011). Explaining physicians' acceptance of EHCR systems: An extension of TAM with trust and risk factors. Computers in Human Behavior, 27(1), 319-332.

23. Ein-Dor, P., Segev, E., \& Orgad, M. (1993). "The Effect of National Culture on IS: Implications for International Information Systems," Journal of Global Information Management, (1: I), Winter, pp. 3344.

24. Evers, V. \& Day, D. (1997).The role of culture in interface acceptance. In Human-Computer Interaction INTERACT'97 (pp. 260-267). Springer US.

25. Fishbein, M. \&Azjen, I. (1975). Belief, attitude, intentions, and behavior: An introduction to theory and research. Reading, MA: Addison-Wesley.

26. Harvey, F. (1999). "National Cultural Differences in Theory and Practice: Evaluating Hofstede's National Cultural Framework," Information Technology \& People, (10: 2), pp. 132-146.

27. Hasan, H. \& Ditsa, G. (1999). "The impact of culture on the adoption of IT: An interpretive study", Journal of Global Information Management, 7(1), 5-15.

28. Hofstede, G. (2011). Dimensionalizing cultures: The Hofstede model in context. Online readings in psychology and culture, 2(1), 8.

29. Hofstede, G. \& Waquet, M. (1994). Vivre dans un monde multiculturel: comprendre nos programmations mentales. Les Ed. d'organisation.

30. Hofstede, G., Hofstede, G. J., \& Minkov, M. (1991). Cultures and organizations: Software of the mind (Vol. 2). London: McGraw-Hill.

31. Holden, R. J. \& Karsh, B. T. (2010). The technology acceptance model: its past and its future in health care. Journal of biomedical informatics, 43(1), 159-172.

32. Hoque, M. R. \& Bao, Y. (2015). Cultural influence on adoption and use of e-Health: evidence in Bangladesh. Telemedicine and e-Health, 21(10), 845-851.

33. Hsieh, P. J. (2015). Physicians' acceptance of electronic medical records exchange: An extension of the decomposed TPB model with institutional trust and perceived risk. international journal of medical informatics, 84(1), 1-14.

34. Hu, P. J., Chau, P. Y., Sheng, O. R. L., \& Tam, K. Y. (1999). Examining the technology acceptance model using physician acceptance of telemedicine technology. Journal of management information systems, 16(2), 91-112.

35. Hung, S. Y., Ku, Y. C., \& Chien, J. C. (2012).Understanding physicians' acceptance of the Medline system for practicing 
evidence-based medicine: A decomposed TPB model. International Journal of Medical Informatics, 81(2), 130-142.

36. Igbaria, M., Zinatelli, N., Cragg, P., \& Cavaye, A.L.M. (1997). "Personal Computing Acceptance Factors in Small Firms : A structural Equation Model, "MIS Quarterly, vol.21, N³, pp.279-305.

37. Kroeber, A. L., \& Kluckhohn, C. (1952). Culture: A critical review of concepts and definitions. Papers. Peabody Museum of Archaeology \& Ethnology, Harvard University.

38. Kukafka, R., Johnson, S. B., Linfante, A., \&Allegrante, J. P. (2003).Grounding a new information technology implementation framework in behavioral science: a systematic analysis of the literature on IT use. Journal of biomedical informatics, 36(3), 218227.

39. Lee, S. G., Trimi, S., \& Kim, C. (2013).The impact of cultural differences on technology adoption. Journal of World Business, 48(1), 20-29.

40. Loth, D. (2006).Le management interculturel. Paris, L'Harmattan, pp.47-48.

41. Muñoz-Leiva, F., Climent-Climent, S., \& Liébana-Cabanillas, F. (2017). Determinants of intention to use the mobile banking apps: An extension of the classic TAM model. Spanish Journal of MarketingESIC, 21(1), 25-38.

42. Myers, M. D. \& Tan, F. B. (2003). Beyond models of national culture in information systems research. Advanced topics in global information management, 2, 14-29.

43. Mathieson, K. (1991). Predicting user intention: Comparing the technology acceptance model with theory of planned behavior. Information Systems Research, 2, 173-191.

44. Mohd, H. \& Syed Mohamad, S. M. (2005). Acceptance model of electronic medical record. Journal of Advancing Information and Management Studies,2(1), 75-92.

45. Mooghali, A. \& Mirghaderi, S. S. (2012). Employees' Intention to Use Web-based Training in South Zagros Oil and Gas Production Company, a Causal Model. Life Science Journal, 9(2).

46. Oumlil, R. (2010). Modèle de prédiction de l'appropriation des technologies de l'information et de la communication et des systèmes d'information par les professionnels de soins : cas de la ville d'Agadir, (Doctoral dissertation, Université Ibn Zohr Agadir, Maroc).

47. Quiguer, S. (2013). Acceptabilité, acceptation et acceptation des Systèmes de Transport Intelligents: élaboration d'un canevas de coconception multidimensionnelle orientée par l'activité (Doctoral dissertation, Université Rennes 2). 
48. Rice, R. E. \& Aydin, C. (1991). Attitudes toward new organizational technology: Network proximity as a mechanism for social information processing. Administrative science quarterly, 219-244.

49. Ryu, S., Ho, S. H., \& Han, I. (2003). Knowledge sharing behavior of physicians in hospitals.Expert Systems with applications, 25(1), 113122.

50. Schepers, J., \& Wetzels, M. (2007). A meta-analysis of the technology acceptance model: Investigating subjective norm and moderation effects. Information \& management, 44(1), 90-103.

51. Srite, M. \& Karahanna, E. (2006).The role of espoused national cultural values in technology acceptance.MIS quarterly, 679-704.

52. Straub, D. W. (1994). The Effect of Culture on IT Diffusion: E-Mail and FAX in Japan and the US. Information Systems Research, 5(1), 23-47.

53. Straub, D. W., Loch, K. D., \& Hill, C. E. (2003). Transfer of information technology to the Arab world: a test of cultural influence modeling. Advanced topics in global information management, 2, 141-172.

54. Straub, D., Keil, M., \& Brenner, W. (1997). Testing the technology acceptance model across cultures: A three country study. Information \& management, 33(1), 1-11.

55. Straub, D., Loch, K., Evaristo, R., Karahanna, E., \& Srite, M. (2002).Toward a theory-based measurement of culture.Human factors in information systems, 10(1), 61-65.

56. Szajna, B. (1996). Empirical evaluation of the revised technology acceptance model. Management science, 42(1), 85-92.

57. Tan, B.C.Y., Watson, R.T., \& Wee, K.L. (1995) National Culture and Group Support Systems: Filtering Communication to Dampen Power Differentials, European Journal of Information Systems, Vol. 4 N², p.82-92.

58. Triandis, H. C. (1980). Values, attitudes, and interpersonal behavior (pp. 195- 259) Nebraska symposium on motivation, 1979: Belifs, attitudes and values. Lincoln, NE: University of Nebraska Press.

59. Van Slyke, C., Belanger, F., \& Sridhar, V. (2005). A comparison of American and Indian consumers' perceptions of electronic commerce. Information Resources Management Journal (IRMJ), 18(2), 24-40.

60. Veltri, N. F., Krasnova, H., \& Elgarah, W. (2011, August). Online Disclosure and Privacy Concerns: a Study of Moroccan and American Facebook Users. In AMCIS. 
61. Venkatesh, V. \& Davis, F. D. (2000). A theoretical extension of the technology acceptance model: Four longitudinal field studies. Management science, 46(2), 186-204.

62. Venkatesh, V. \& Bala, H. (2008).Technology Acceptance Model 3 and a Research Agenda on Interventions. Decision Sciences, 39(2), 273-315. doi:10.1111/j.1540 -5915.2008.00192

63. Vörös, T. \& Choudrie, J. (2011). Uncertainty Avoidance and Technology Acceptance in Emerging Economies: A Comparative Study. In SIG Globdev 4th Ann Conf, Shanghai, China.

64. Wu, J. H., Shen, W. S., Lin, L. M., Greenes, R. A., \& Bates, D. W. (2008). Testing the technology acceptance model for evaluating healthcare professionals' intention to use an adverse event reporting system. International Journal for Quality in Health Care, 20(2), 123129.

65. Wu, B. \& Chen, X. (2017). Continuance intention to use MOOCs: Integrating the technology acceptance model (TAM) and task technology fit (TTF) model. Computers in Human Behavior, 67, 221232.

66. Wu, L., Li, J. Y., \& Fu, C. Y. (2011). The adoption of mobile healthcare by hospital's professionals: An integrative perspective. Decision Support Systems, 51(3), 587-596. 